\title{
The Influence of Fortification of Dark Chocolate with Sea Buckthorn and Mulberry on the Content of Biologically Active Substances
}

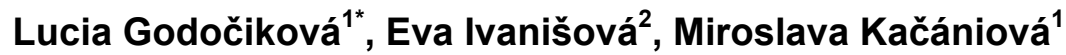 \\ ${ }^{1}$ Department of Microbiology, Slovak University of Agriculture in Nitra, \\ Tr. A. Hlinku 2, 94976 Nitra, Slovak Republic \\ 2 Department of Storage and Processing of Plant Products, Slovak University of Agriculture in Nitra, \\ Tr. A. Hlinku 2, 94976 Nitra, Slovak Republic
}

\begin{abstract}
The aim of our study was to assess the impact of mulberry (Morus nigra L.) and sea buckthorn (Hippophae rhamnoides L.) addition on improvement of antioxidant characteristics of dark chocolate. For evaluation of total polyphenolic content we used Folin-Ciocalteu reagent, for total content of flavonoids spectrophotometric assay based on a formation of coloured flavonoid-aluminium complex was used and for the content of total phenolic acids was used method using Arnow's reagent. Three different methods were also used for measuring the antioxidant activity of samples: DPPH scavenging activity, reducing power method and phosphomolybdate method. Obtained results showed, that compared to plain dark chocolate used as control, chocolate enriched with mulberry exhibited higher polyphenolic content and antioxidant capacity. On the other hand, enrichment with sea buckthorn didn't show such significant improvement in antioxidant characteristics, but increased the levels of bioactive compounds despite the lower content of cocoa solids.
\end{abstract}

Key words: chocolate, enrichment, fortification, antioxidant activity, DPPH, polyphenols, flavonoids.

\section{Introduction}

Chocolate has become one of the most popular foods worldwide, because of its sweet and delicious taste [1]. Chocolate is a very unique product, representing both a confectionery treat often avoided due to its high calorific value, but is also promoted as a functional food with potential health benefits, attributed to its rich bioactive profile [2]. Cocoa has the highest flavanol content of all foodstuffs on a weight basis and therefore is a significant contributor to the total dietary intake of flavonoids. In fact, for many people, cocoa products represent a larger portion of the diet than foodstuffs containing similar bioactive compounds, such as green tea, wine or soy beans [3].

\section{* Corresponding author: Lucia Godočiková, l.godocikova@gmail.com}

(cc) BY-NC-ND 2017 Lucia Godočiková et al., published by De Gruyter Open. This work was licensed under the Creative Commons Attribution-NonCommercialNoDerivs 3.0 License
Polyphenols in cocoa beans are found in the pigment cells of the cotyledons. Its polyphenolic composition depends on many factors, such as type, geographical origin growing conditions, and maturity of cocoa fruit, as well as fermentation and food processing [4]. Potential effectiveness of these ingredients depends on their bioavailability influenced by food matrix. The final concentration of flavanols depends on the used processing treatment applied to reduce their characteristic bitterness and to gain required consistency [5]. It has recently been discovered that dark chocolate has a number of health benefits including protection against heart disease, regulation of blood sugar and insulin dependence, stroke prevention, antioxidant protection, alleviation of cold and cough, reduced cancer risk, reduced risk of colon cancer, slowing aging, increased immune function, Alzheimer's protection, reduction of premenstrual syndrome and prevention of alopecia [6]. A great number of functional food 
products that have been already introduced into the market because consumers became more interested in healthy lifestyle and nutrition, but only few attempts have been made to produce chocolates with the addition of naturally derived polyphenolic compounds [7]. Black mulberry (Morus nigra L.) is a good source of bioactive compounds, especially of anthocyanin [8]. Sea buckthorn (Hippophae rhamnoides L.) is appreciated especially for the high content of vitamins, flavonoids and organic acids [9]. Therefore the aim of our work was to evaluate the impact of addition of sea buckthorn and black mulberry on enhancing biological activity and antioxidant potential of dark chocolates.

\section{Material and Methods}

Biological materials. The chocolate samples evaluated in this study were made and kindly supplied by Slovakian chocolate-producing company. Enrichment ingredients and their additions to plain dark chocolate, used as control (SKO), are listed in Table 1.

Table 1

The content of fruit addition and cocoa solids

\begin{tabular}{|l|l|c|c|}
\hline & \multicolumn{1}{|c|}{ Enrichment } & Addition & $\begin{array}{c}\text { Cocoa } \\
\text { mass }\end{array}$ \\
\hline SK1 & Sea buckthorn & $20 \%$ & $60 \%$ \\
\hline SK2 & Black mulberry & $15 \%$ & $65 \%$ \\
\hline SK0 & Plain dark (control) & - & $80 \%$ \\
\hline
\end{tabular}

Chemicals. All chemicals were analytical grade and were purchased from CentralChem (Slovak Republic) and Sigma Aldrich (USA).

Sample extracts preparation. All samples were mashed into small pieces and then homogenized in a mortar. Lipid elimination from samples was not executed. Although in most of the studies lipids from chocolates have been removed, there are some studies in the literature which did not eliminate them [10]. Then $0.25 \mathrm{~g}$ of homogenized sample was extracted with $20 \mathrm{~mL}$ of $80 \%$ ethanol for 2 hours in a shaker (GFL 3005, Germany). After centrifugation at 4000 RPM (Rotofix 32A, Hettich, Germany) for 10 minutes and subsequent filtration, the supernatant was used for measurements. All analyses were done in triplicate.

Determination of total phenolic content. Total polyphenol content was measured using method of Singleton and Rossi [11] using Folin-Ciocalteu reagent. Sample extract in volume of $100 \mu$ was mixed with $100 \mu$ l of the Folin-Ciocalteu reagent, $1000 \mu \mathrm{l}$ of $20 \%(\mathrm{w} / \mathrm{v})$ sodium carbonate and 8.8 $\mathrm{mL}$ of distilled water respectively. After 30 minutes of resting in dark place the absorbance at $700 \mathrm{~nm}$ was measured using spectrophotometer Jenway (6405 UV/Vis, England). Gallic acid (25 - 250 $\mathrm{mg} \cdot \mathrm{L}^{-1} ; \mathrm{r}^{2}=0.9978$ ) was used as the standard and the results were expressed in mg GAE (gallic acid equivalents) per gram of chocolate.

Determination of total flavonoid content. Content of total flavonoids was determined using the modified method by Willett [12]. A $0.5 \mathrm{~mL}$ of sample extract was mixed with $0.1 \mathrm{~mL}$ of $10 \%$ $(\mathrm{w} / \mathrm{v})$ ethanolic solution of aluminium chloride, 0.1 $\mathrm{mL}$ of $1 \mathrm{M}$ sodium acetate and $4.3 \mathrm{~mL}$ of distilled water. After 30 minutes of resting in dark place the absorbance at $415 \mathrm{~nm}$ was measured using the spectrophotometer Jenway (6405 UV/Vis, England). Quercetin (0.01 - $\left.0.5 \mathrm{mg} \cdot \mathrm{L}^{-1} ; \mathrm{r}^{2}=0.9977\right)$ was used as the standard and the results were expressed in mg.g ${ }^{-1}$ QE (quercetin equivalents).

Determination of total content of phenolic acids. Content of total phenolic acids was determined using method by Farmakopea Polska [13]. A 0.5 $\mathrm{mL}$ of sample extract was mixed with $0.5 \mathrm{~mL}$ of $0.5 \mathrm{M}$ hydrochloric acid, $0.5 \mathrm{~mL}$ Arnow's reagent $\left(10 \% \mathrm{NaNO}_{2}+10 \% \mathrm{Na}_{2} \mathrm{MoO}_{4}\right), 0.5 \mathrm{~mL}$ of $1 \mathrm{M}$ sodium hydroxide $(\mathrm{w} / \mathrm{v})$ and $0.5 \mathrm{~mL}$ of water. Absorbance at $490 \mathrm{~nm}$ was measured using the spectrophotometer Jenway (6405 UV/Vis, England). Caffeic acid $\left(1-200 \mathrm{mg} \cdot \mathrm{L}^{-1}, \mathrm{r}^{2}=0.9996\right)$ was used as a standard and the results were expressed in $\mathrm{mg}^{-1}$ caffeic acid equivalents (CAE).

$D P P H$ scavenging activity. Radical scavenging activity of samples was measured using 2,2diphenyl-1-picrylhydrazyl (DPPH) [14]. The extract $(0.4 \mathrm{~mL})$ was mixed with $3.6 \mathrm{~mL}$ of DPPH solution (0.025 g DPPH in $100 \mathrm{~mL}$ ethanol). After 10 minutes of resting in dark place, absorbance of the sample extract was determined using the spectrophotometer Jenway (6405 UV/Vis, England) at $515 \mathrm{~nm}$. Trolox (6-hydroxy-2,5,7,8tetramethylchroman-2-carboxylic acid) (10 - 100 $\mathrm{mg} . \mathrm{L}^{-1} ; \mathrm{r}^{2}=0.9881$ ) was used as the standard and the results were expressed in $\mathrm{mg}^{-1} \mathrm{~g}^{-1}$ Trolox equivalents.

Reducing power. Reducing power of samples was determined by the method of Oyaizu [15]. One millilitre of sample extract was mixed with $5 \mathrm{~mL}$ PBS (phosphate buffer with $\mathrm{pH} 6.6$ ) and $5 \mathrm{~mL}$ of 1 $\%$ potassium ferricyanide (w/v). Mixture was stirred thoroughly and heated in water bath for 20 minutes at $50{ }^{\circ} \mathrm{C}$. After cooling to room temperature, $5 \mathrm{~mL}$ of $10 \%$ trichloroacetic acid was added. $5 \mathrm{~mL}$ of mixture was pipetted into the test tube and mixed with $5 \mathrm{~mL}$ of distilled water and $1 \mathrm{~mL}$ of $0.1 \%(\mathrm{w} / \mathrm{v})$ ferric chloride solution. Absorbance at $700 \mathrm{~nm}$ was measured using the spectrophotometer Jenway (6405 UV/Vis, England). Reducing power was expressed in mg.g ${ }^{-1}$ Trolox equivalents, using Trolox (6- 
hydroxy-2,5,7,8-tetramethylchroman-2-carboxylic acid) $\left(10-100 \mathrm{mg} \cdot \mathrm{L}^{-1} ; \mathrm{r}^{2}=0.9974\right)$ as the standard and results were expressed in $\mathrm{mg}^{-1}$ Trolox equivalents.

Phosphomolybdate method. Phosphomolybdic method was determined by a method of Prieto et al. [16]. Monopotassium phosphate $(2.8 \mathrm{~mL}, 0.1$ $\mathrm{M}, \mathrm{w} / \mathrm{v})$ was mixed with sulfuric acid $(6 \mathrm{~mL}, 1 \mathrm{M})$, ammonium molybdate $(0.4 \mathrm{~mL}, 0.1 \mathrm{M}, \mathrm{w} / \mathrm{v})$, distilled water $(0.8 \mathrm{~mL})$ and $1 \mathrm{~mL}$ of sample extract. Test tubes were mixed thoroughly and heated in water bath for 120 minutes at $90{ }^{\circ} \mathrm{C}$. After cooling, absorbance at $700 \mathrm{~nm}$ was measured using the spectrophotometer Jenway (6405 UV/Vis, England). Antioxidant activity was expressed in $\mathrm{mg}^{-1} \mathrm{~g}^{-1}$ Trolox equivalents $(10-1000$ mg. $\left.L^{-1}, r^{2}=0.9975\right)$.

Statistical analysis. All measurements and analyses were carried out in triplicate. Experimental data were evaluated by basic statistical variability indicators using the Microsoft ${ }^{\mathrm{TM}}$ Excel $\AA$ program. Dependency rate between the tested traits was expressed using the linear correlation analysis.

\section{Results and Discussion}

Total polyphenols content. Polyphenols can be found in a wide variety of foodstuffs such as fruit, vegetables, tea, coffee and red wine. Dark chocolate was shown to have more polyphenols than milk or white chocolate, because it contains more cocoa and polyphenols can be less bioavailable in the presence of milk [17]. According to literature, there was found a high positive correlation between amount of cocoa solids and phenolic compounds [10]. Total content of polyphenols of all samples is shown in Table 2. Samples enriched with mulberry and even sea buckthorn had more polyphenols than control sample. Better results were obtained with black mulberry, even when the addition was in lower amount than sea buckthorn. Komes et al. [18] also studied the effect of addition of dried fruits (dried prunes, dried papaya, dried apricots, dried raisins and dried cranberries) on bioactive content of milk and dark chocolates. It was shown that the addition of dried fruits especially prunes and cranberries increased the total phenolic content of dark and milk chocolates. Cervellati et al. [19] also supported our results with conclusion that artisanmade chocolate can preserve more biologically active polyphenolic compounds than factory-made ones. It is difficult to compare the results, because the concentration of all polyphenols can vary tremendously among different cocoa-containing foods. This concentration can also vary depending on the source of the beans, the processing conditions, and how the chocolates were manufactured [20].

\section{Characteristic of samples}

Table 2

\begin{tabular}{|l|c|c|c|}
\hline & $\begin{array}{c}\text { TPC } \\
\left(\mathbf{m g ~ G A . ~}^{-1}\right)\end{array}$ & $\begin{array}{c}\text { TFC } \\
\left(\mathbf{m g ~ Q E . ~}^{-1}\right)\end{array}$ & $\begin{array}{c}\text { TPA } \\
\left.\text { (mg CAE. }^{-1}\right)\end{array}$ \\
\hline SK1 & $8.07 \pm 0.62$ & $1.17 \pm 0.06$ & $6.64 \pm 0.25$ \\
\hline SK2 & $8.83 \pm 1.29$ & $1.30 \pm 0.11$ & $9.51 \pm 0.20$ \\
\hline SK0 & $7.32 \pm 1.02$ & $0.52 \pm 0.25$ & $6.68 \pm 0.29$ \\
\hline
\end{tabular}

Total flavonoid content. Flavonoids are an important class of plant pigments, naturally found in fruit and vegetables. This class of naturally occurring polyphenolic compounds which cannot be synthesized by humans possesses a series of biological properties, acting on biological systems as antioxidants [21]. Cocoa and also dark chocolate have the highest flavanol content of all foods on a per-weight basis and can therefore significantly contribute to the total dietary intake of flavonoids [17]. The amount of total flavonoid content (TFC) of our samples is shown in Table 2. It can be seen that the content of total flavonoids is almost twice as high as its content in control sample. Best results were again obtained with mulberry enrichment. There was also found high positive correlation with content of total polyphenols $(r=0.9319)$. The percentage of cocoa is not a reliable indicator of the flavanol content present in a given product [22]. Calado et al. [21] showed, that bitter chocolate can have higher flavonoid content compared to some kinds of cooked vegetables and advises, that people who don't like foods like broccoli or eggplant (daily dose 20 - $26 \mathrm{~g}$ ) could eat more chocolate (daily dose only $8 \mathrm{~g}$ ).

Total phenolic acids content. Phenolic acids are ubiquitous in edible vegetable, fruits, and nuts. They are also present in coffee, tea and especially in berries. They are extensively studied because of their bioactive properties and there is an evidence of their role in disease prevention. Recent interest in phenolic acids also stems from their potential protective role against oxidative stress, inflammation, diabetes and cancer in experimental studies [23-25]. The amount of total phenolic acids was in this case higher in control sample than in sample enriched with sea buckthorn. Black mulberry increased the amount of TPA in dark chocolate. Hundreds of phenolic acids have been identified in nature. For example, protocatechuic acid is a hydroxybenzoic acid that can be found in many foods and it is also the most abundant phenolic acid $(69.16 \%)$ found in cocoa liquor. This acid was shown to have several physiological functions including 
antioxidant, antibacterial activity and antimutagenic activity [25-26].

$D P P H$ scavenging activity. Analysis using DPPH radical is most frequently used to determine the antioxidant capacity of foods. Antioxidant activity of our samples measured by this method is shown in Figure 1. Best results were again obtained for mulberry enriched dark chocolate. Vertuani et al. also reported that in general, decreasing the percentage of non-fat cocoa solids causes a decrease in the antioxidant activity associated with a lower content of total polyphenols, as can be seen in our case [27].

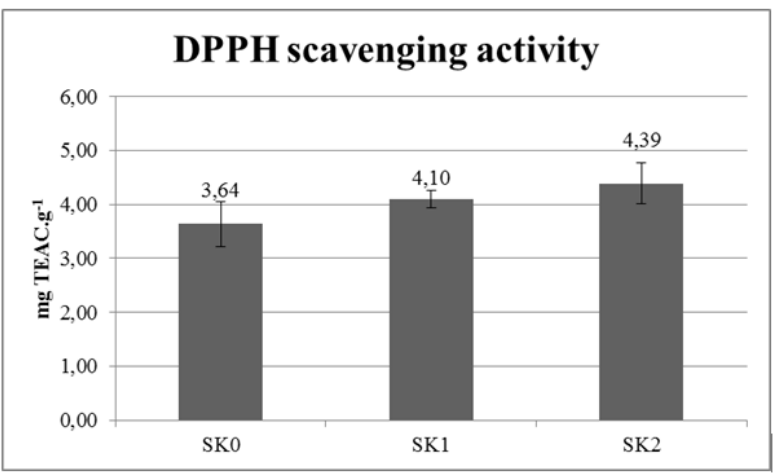

Fig. 1. DPPH scavenging activity

Black mulberry and sea buckthorn are very rich sources of important biologically active compounds and can contribute to higher antioxidant activity of dark chocolates with even lower cocoa solids, in comparison to plain dark chocolate used as control [8; 28]. There was also found high positive correlation between antioxidant activity by DPPH and total content of polyphenols $(r=0.9910)$ and also total flavonoid content $(r=0.9720)$.

Reducing power. The reducing power of a compound serves as a significant indicator of its potential antioxidant capacity.

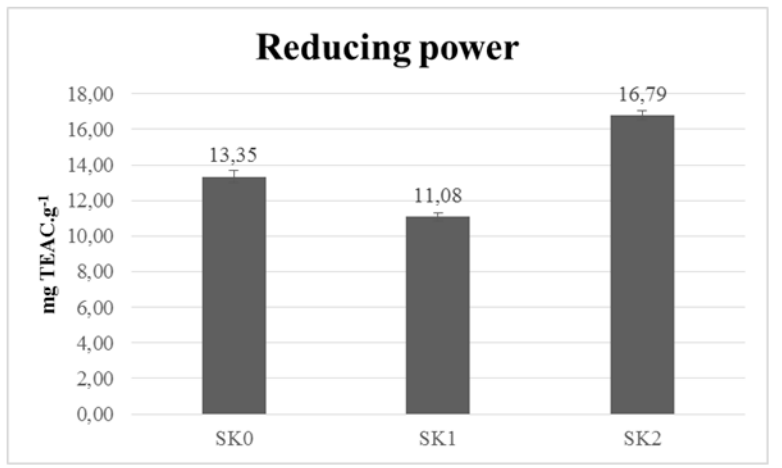

Fig. 2. Reducing power method
The reducing power assay is based on electron donating activity, which is main mechanism of phenolic antioxidant action [29]. Figure 2 shows the reducing power of the examined samples.

Enrichment of dark chocolate with black mulberry showed the highest improvement in antioxidant activity measured by reducing power method. Sea buckthorn addition had even lower antioxidant activity than control sample by this assay, but this chocolate has the lowest cocoa solids content. Reducing power of our samples was in high correlation with content of total phenolic acids ( $r=$ 0.9235). Additionally, it must be considered that the antioxidant activity of a mix is not the sum of the antioxidant activities of each of the components, however, the interactions of the compounds in between might generate synergic or inhibitors effects [30].

Phosphomolybdate method. This method is based upon the spectrophotometric quantitation of total antioxidant capacity [16]. Black mulberry showed the best antioxidant properties determined by this method. Antioxidant activity of chocolate with sea buckthorn was even lower than antioxidant activity of control sample.

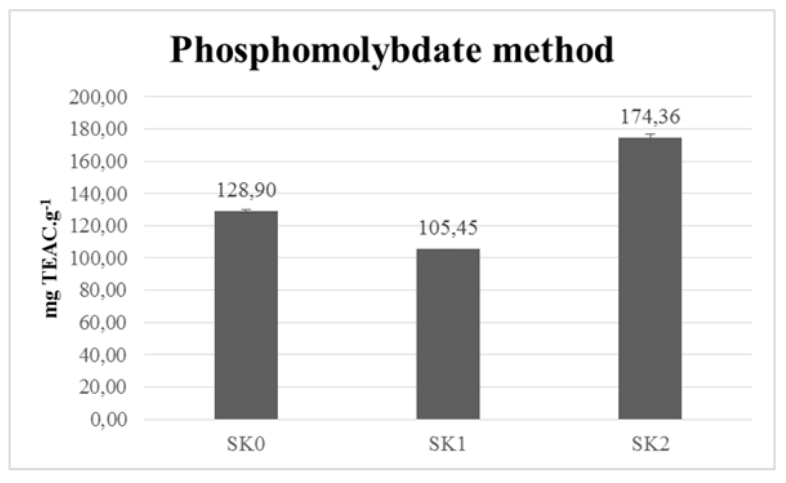

Fig. 3. Phoshomolybdate method

This may be again due to the fact, that because of high addition of dried fruit the amount of cocoa solids was reduced. The differences in antioxidant capacity of different fruits enrichments may be attributed to differences in their chemical compositions. Antioxidant activity measured by this method showed high positive correlation with their reducing power $(r=0.9979)$ and even with total content of phenolic acids $(r=0.9463)$.

\section{Conclusions}

Based on the above findings we can conclude, that dark chocolate is in general very good source of biologically active compounds and dietary antioxidants. Our results also proved that enrichment with specific types of dried fruits, for example with black mulberry, can improve that 
characteristic even with lower cocoa solids content. Results of this work can be an important tool for next scientific works and for food producers.

\section{Acknowledgements}

Authors are grateful to the Slovakian chocolateproducing company for cooperation and for supplying the samples used in the study. The study was supported from the European Community fund project No. 26220220180: Building Research Centre „AgroBioTech" and VEGA 1/0411/17.

\section{References}

1. Dong, J.Y., Iso, H., Yamagishi, K., Sawada, N., \& Tsugane, S. (2017). Chocolate consumption and risk of stroke among men and women: A large populationbased, prospective cohort study. Atherosclerosis, 260, 8-12, DOI: http://dx.doi.org/10.1016/j.atherosclerosis.2017.03.004 2. Belščak-Cvitanović, A., Komes, D., Durgo, K., Vojvodić, A., \& Bušić, A. (2015). Nettle (Urtica dioica L.) extracts as functional ingredients for production of chocolates with improved bioactive composition and sensory properties, Journal of Food Science and Technology, 52 (12), 7723-7734, doi: 10.1007/s13197015-1916-y

3. Martín, M. A., Goya, L., \& Ramos, S. (2016). Preventive effects of cocoa and cocoa antioxidants in colon cancer, Diseases, 4(1), 6, doi:10.3390/diseases4010006

4. Ibrić, A. \& Ćavar, S. (2014). Phenolic Compounds and Antioxidant Activity of Cocoa and Chocolate Products, Bulletin of the Chemists and Technologists of Bosnia and Herzegovina, 42, 37-40.

5. Konar, N., Toker, O. S., Oba, S., \& Sagdic, 0. (2016). Improving functionality of chocolate: A review on probiotic, prebiotic, and/or synbiotic characteristics, Trends in Food Science \& Technology, 49, 35-44, https://doi.org/10.1016/j.tifs.2016.01.002

6. Haritha, K., Kalyani, L., \& Rao, A. L. (2014). Health Benefits of Dark Chocolate, Journal of Advanced Drug Delivery, 1 (4), 184-94.

7. Belščak-Cvitanović, A., Komes, D., Benković, M., Karlović, S., Hečimović, D. J., \& Bauman, I. (2012). Innovative formulations of chocolates enriched with plant polyphenols from Rubus idaeus L. leaves and characterization of their physical, bioactive and sensory properties, Food Research International, 48, 820-830, https://doi.org/10.1016/j.foodres.2012.06.023

8. Kucelova, L., Grygorieva, O., Ivanišová, E., Terentjeva, M., \& Brindza, J. (2016). Biological properties of black mulberry-derived food products (Morus nigra L.), Journal of Berry Research, 6(3), 333343, DOI: 10.3233/JBR-160141

9. Mendelová, A., Mendel, L'., Czako, P., \& Mareček, J. (2016). Evaluation of carotenoids, polyphenols content and antioxidant activity in the sea buckthorn fruit, Potravinarstvo Slovak Journal of Food Sciences, 10 (1), 59-64, doi:10.5219/551

10. Cerit, İ., Şenkaya, S., Tulukoğlu, B., Kurtuluş, M., Seçilmişoğlu, Ü. R., Demirkol O. (2016). Enrichment of functional properties of white chocolates with cornelian cherry, spinach and pollen powders, GIDA/The Journal of FOOD, 41 (5), 311-316.

11. Singleton, V. L. \& Rossi, J. A. (1965). Colorimetry of total phenolics with phosphomolybdicphosphotungstic acid reagents, American Journal of Enology and Agricultural, 16, 144-158.

12. Willett, W. C. (2002). Balancing life-style and genomics research for disease prevention, Science, 292(5568), 695-698, DOI: 10.1126/science.1071055

13. Farmakopea Polska, The Polish Farmaceutical Society (1999), pp. 880-881.

14. Sánchés-Moreno, C., Larrauri, A., \& SauraCalixto, F. (1998). A procedure to measure the antioxidant efficiency of polyphenols, Journal of the Science of Food and Agriculture, 76 (2), 270-276.

15. Oyaizu, M. (1986). Studies on products of browning reaction - antioxidative activities of products of browning reaction prepared from glucosamine, Japanese journal of nutrition, 44 (6), 307-314.

16. Prieto, P., Pineda, M., \& Aguilar, M. (1999). Spectrophotometric quantitation of antioxidant capacity through the formation of a phosphomolybdenum complex: specific application to the determination of vitamin E, Analytical Biochemistry, 269(2), 337-341, https://doi.org/10.1006/abio.1999.4019

17. Beckett, S. T. (2008). The Science of Chocolate, $2^{\text {nd }}$ ed., Cambridge: The Royal Society of Chemistry, pp. 252.

18. Komes, D., Belščak-Cvitanović, A., Škrabal, S., Vojvodić, A., \& Bušić, A. (2013). The influence of dried fruits enrichment on sensory properties of bitter and milk chocolates and bioactive content of their extracts affected by different solvents, LWT - Food Science and Technology, 53 (1), 360-369, https://doi.org/10.1016/j.Iwt.2013.02.016

19. Cervellati, R., Greco, E., Costa, S., Guerra, M. C., \& Speroni, E. (2008). A comparison of antioxidant properties between artisan-made and factory-produced chocolate. International journal of food science \& technology, 43 (10), 1866-1870, DOI: 10.1111/j.13652621.2008.01765.x

20. Cooper, K. A., Campos-Giménez, E., Jimenéz Alvarez, D., Nagy, K., Donovan, J. L., \& Williamson, G. (2007). Rapid reversed phase ultra-performance liquid chromatography analysis of the major cocoa polyphenols and inter-relationships of their concentration in chocolate, Journal of Agricultural and Food Chemistry, 55, 2841-2847, DOI: 10.1021/jf063277c

21. Calado, J. C. P., Albertão, P. A., De Oliveira, E. A., Letra, M. H. S., Sawaya, A. C. H. F., \& Marcucci, M. C. (2015). Flavonoid Contents and Antioxidant Activity in Fruit, Vegetables and Other Types of Food, Agricultural Sciences, 6 (4), 426-435, http://dx.doi.org./10.4236/as.2015.64042

22. Latham, L. S., Hensen, Z. K., \& Minor, D. S. (2013). Chocolate - Guilty Pleasure or Healthy Supplement?, The Journal of Clinical Hypertension, 16 (2), 101-106, DOI: 10.1111/jch.12223

23. Vinayagam, R., Jayachandran, M., \& Xu, B. (2016). Antidiabetic Effects of Simple Phenolic Acids: A Comprehensive Review. Phytotherapy research, 30 (2), 184-199, DOI: 10.1002/ptr.5528 
24. Heleno, S. A., Martins, A., Queiroz, M. J. R. P., \& Ferreira, I. C. F. R. (2015). Bioactivity of phenolic acids: Metabolites versus parent compounds: A review. Food Chemistry, 173 , https://doi.org/10.1016/j.foodchem.2014.10.057

25. Zamora-Ros, R., Rothwell, J. A., Scalbert, A., Knaze, V., Romieu, I., Slimani, N., Fagherazzi, G., Perquier, F., Touillaud, M., Molina-Montes, E., Huerta, J. M., Barricarte, A., Amiano, P., Menéndez, V., Tumino, R., de Magistris, M. S., Palli, D., Ricceri, F., Sieri, S., Crowe, F. L., Khaw, K. T., Wareham, N. J., Grote, V., Li, K., Boeing, H., Förster, J., Trichopoulou, A., Benetou, V., Tsiotas, K., Buenode-Mesquita, H. B., Ros, M., Peeters, P. H., Tjønneland, A., Halkjær, J., Overvad, K., Ericson, U., Wallström, P., Johansson, I., Landberg, R., Weiderpass, E., Engeset, D., Skeie, G., Wark, P., Riboli, E., \& González, C. A. (2013). Dietary intakes and food sources of phenolic acids in the European Prospective Investigation into Cancer and Nutrition (EPIC) study, British Journal of Nutrition, 110 (8), 15001511 , DOI:
26. Zhou, S., Seo, S., Alli, I., \& Chang, Y. W. (2015). Interactions of caseins with phenolic acids found in chocolate, Food Research International, 74, 177-184, https://doi.org/10.1016/j.foodres.2015.05.006

27. Vertuani, S., Scalambra, E., Vittorio, T., Bino, A., Malisardi, G., Baldisserotto, A., \& Manfredini, S. (2014). Evaluation of Antiradical Activity of Different Cocoa and Chocolate Products: Relation with Lipid and Protein Composition, Journal of Medicinal Food, 17(4), 512-516, https://doi.org/10.1089/jmf.2013.0110

28. Suryakumar, G. \& Gupta, A. (2011). Medicinal and therapeutic potential of Sea buckthorn (Hippophae rhamnoides L.). Journal of Ethnopharmacology, 138, 268-278, https://doi.org/10.1016/j.jep.2011.09.024

29. Aadil, K. R., Barapatre, A., Sahu, S., Jha, H., \& Tiwary, B. N. (2014). Free radical scavenging activity and reducing power of Acacia nilotica wood lignin. International journal of biological macromolecules, 67 , 220-227, https://doi.org/10.1016/j.ijbiomac.2014.03.040 30. Fernández, V., Yee, A., Sulbarán, B., \& Peña, J. (2014). Actividad antioxidante y contenido de polifenoles en chocolates comerciales venezolanos, Revista de la Facultad de Agronomía, 31, 129-144. 